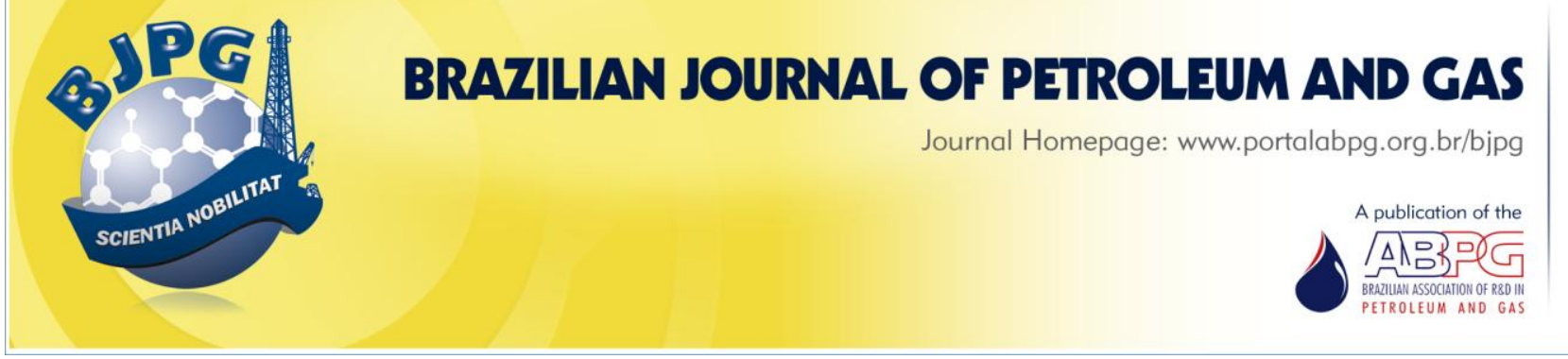

\title{
MODELING THE DISPERSION PHENOMENON IN BATCH TRANSFER OPERATIONS BY THE THEORY OF STRUCTURED MIXTURE
}

\author{
${ }^{\text {a }}$ Oliveira, J. L. ${ }^{1}$ \\ a Department of Mechanical Engineering, Universidade Federal Fluminense
}

\begin{abstract}
This paper investigates the design of a model based on the theory of structured mixture that retains the character of one-dimensional models from the literature, simultaneously being able to estimate the mixing volume with consistency. The determination of the mixing volume in batch transfer operations based on this novel approach can facilitate the understanding of which parameters affect their growth, and even the optimization of multiproduct pipeline operations, in order to reduce the mixing volume. Among other things, the proposed study can generate considerable indirect economic impacts, by providing transported goods with higher quality control, and enabling more efficient planning of the pipeline operations with regard to implementation of pumping stops, thereby providing operational flexibility and reliability.
\end{abstract}

\section{KEYWORDS}

continuum mechanics; mixing volume; batch transfer; theory of mixtures; multiproduct pipeline operation

\footnotetext{
${ }^{1}$ To whom all correspondence should be addressed.

Address: UFF - Postgraduate Program in Mechanical Engineering, Rua Passos da Pátria, 156 / Bloco E - sala 213 - Campus da Praia Vermelha - São Domingos - Niterói, RJ, BRASIL - CEP 24.210-240

Telephone/Fax number: +55(21) 2629-5591 / 2629-5592 | e-mail: jorge@mec.uff.br doi:10.5419/bjpg2010-0014
} 


\section{INTRODUCTION}

The transportation of oil products in long pipelines is a common practice in the petroleum industry and often involves sequential displacement of at least two dissimilar products, or different purity grades of one product in the same line. This type of operation is called batch transfer, and can be in practice performed in two different ways. The first is to use physical separators, usually pigs or scraper balls, in order to prevent the mixing process and subsequent product contamination at interfaces. In this type of operation, physical separators should be properly aligned and connected with each pumping station, thereby requiring skilled labor and time to perform these tasks. In particular, the operation with pigs or scrapers in pipelines where there are numerous intermediate pumping stations may become technically unfeasible. In the second way, commonly used when operational and economic issues arise, no physical separators are used, which ultimately enables the formation of a mixing zone at the products interfaces, as illustrated in Figure 1. After covering the pipeline, the mixing zone should be adequately quantified in terms of degradation of products transported or stored in a specific mixing tank, for subsequent re-processing at the refinery in situations where there is incompatibility of products (Botros, 1984; Coimbra, 1981; Drew and Passman, 1998; Tepedino et al., 2007).

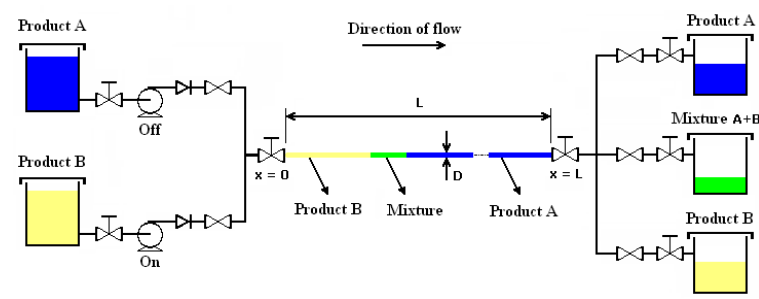

Figure 1. Schematic representation of a batch transfer of two products - generically labeled as products $A$ and $B-$ and a pipeline in the absence of physical separators.

In this case, it is initially assumed that the product identified as $A$ is already being pumped when, at a given moment, product $B$ is inserted in line. After the adequate alignment of tanks, the pump responsible for the displacement of product $A$ is turned off by setting on the pump connected to the tank that stores product $B$. From this moment on, product $B$ starts to push product $A$ through the line by initiating the formation of a mixing zone at the products interface. Due to this type of arrangement, product $B$ is called a fluid shifter while product $A$ is called the displaced fluid.

From an economic standpoint, the formation of mixing zones in batch transfers implies additional costs associated with transportation of the mixture back to the refinery and its re-processing. Aiming to reduce the costs associated with the batch transfer, the volume of the mixing zone should be as small as possible, especially when this mixture can not be diluted with other products, for an example when the displaced products are diesel and gasoline (Tepedino et al., 2007). From an operational viewpoint, the prediction of the mixing zone extent through mechanical models is an important factor, not only at the implementation stage but also when planning the transfer, allowing, a priori, to monitor the volume required to pack the mixture and identify key issues responsible for the growth of the mixing zone during the transfer.

In order to better characterize the peculiarities associated with the batch transfer in the absence of physical separators, it should be noted that this operation involves the displacement of a large variety of products over distances that can reach hundreds of kilometers. Thus, the existence of more than one interface along the line, the injection and withdrawal of products in intermediate pumping stations, different diameters and different topographic dimensions, as well as the occurrence of shutdowns and accidental stops of the pumping operations are key factors that could significantly affect the mixing volume. It should be emphasized that there are no onedimensional models available in the literature that allow to adequately quantify these parameters and their effects on batch transfer operations. Therefore, the methodology used in this article, based on a software developed in Fortran ${ }^{\circ}$, is founded on the structured mixing theory, retaining the character of one-dimensional models and simultaneously being able to estimate the mixing volume or the length of the mixing zone with consistency. In this paper, we aim to show the influence of the speed with which the batch transfer is conducted and also the influence of the pipeline extension on the mixing volume. 


\section{MATERIALS AND METHODS}

In order to better characterize the phenomenon in question, one must consider the batch transfer in which product $A$ is the displaced fluid and product $B$ is the shifting fluid, as previously characterized in Figure 1 . Let $t$ and $s$ be independent variables that respectively represent the time and axial position along the centerline of the pipeline, upstream the pumping station and downstream the receiving station, where $L$ is the total length of the duct. This implies that $C_{i}(s, t) \in[0,1]$, with $i \in\{A, B\}$ being the average time of concentration of fluid $i$ inside the mixture at the cross section of the duct in $s$ and $t$. Mathematically, $C_{i}(s, t)$ is defined by:

$$
C_{i}(s, t):=\frac{1}{2 \Delta t \mathrm{~A}} \int_{A}\left[\int_{t-\Delta t}^{t+\Delta t} \hat{C}_{i}(s, r, \theta, t)\right] r d r d \theta
$$

where $r$ and $\theta$ refer to radial and circumferential coordinates, $A$ is the cross-sectional area of the duct and $2 \Delta t$ is a time period, long enough to eliminate the fluctuations of the turbulence and small enough to capture changes in the concentration camp $\hat{C}_{i}(s, r, \theta, t)$, with $C_{A}+C_{B}=1$.

Under certain circumstances, at the beginning of the batch transfer, concentration can be represented as a leap in $s=0$. For example, suppose that we work with the concentration of fluid $B\left(C_{B}\right)$, and then jumps occur as seen in Figure 2 , which illustrates the configuration of the mixing zone in terms of the concentration of product $B$ at different positions on a continuous transfer duct. During transfer, a mixing zone is formed on the edge of two adjacent products. The extent of this region increases as the transfer takes place along the line. This phenomenon can be observed in Figure 2 at $t=t_{1}$ and $t=t_{2}$, when the conventional half of the mixture (the material point at which the concentrations are equal to 0.5 ) reaches $s=s_{1}$ and $s=s_{2}$ at the space positions.

For practical implementation, the mixing volume at the tube position $s=s_{i}$ can only be evaluated when the permissible concentrations of product $B$ in $A$, at the beginning of the mixing zone, $C_{B A}$, and that of product $A$ in $B$ at the end of the mixing zone, $C_{A B}$, are specified as shown in Figure 3. Once these values (which are not necessarily equal)

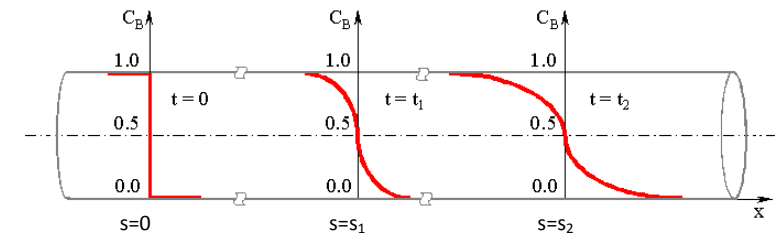

Figure 2. Evolution of spatial mixing zone in a continuous transfer operation.

have been chosen so that the technical specifications of the products are not changed, the volume of mixture at $s=s_{i}$ can be calculated with the following expression:

$V_{i}\left(s=s_{i}\right)=\int_{t_{B A}}^{t_{A B}} Q\left(s=s_{i}, t\right) d t$

in which $Q\left(s=s_{i}, t\right)$ represents the volumetric flow at spatial location $s=s_{i}, t_{B A}$ represents the initial time of the mixing zone with the concentration $C_{B A}$ at position $s=s_{i}$, and $t_{A B}$ is the final time of the mixing zone with concentration (1 $-C_{\mathrm{AB}}$ ) at the position $s=s_{i}$.

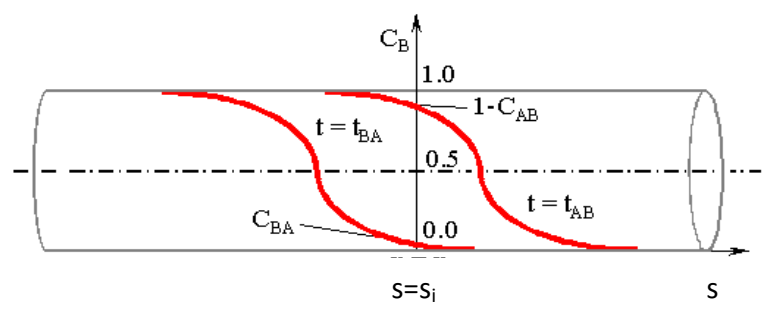

Figure 3. Characterization of the mixing volume at position $s=s_{i}$ at $t=t_{B A}$ and $t=t_{A B}$.

The formation of the products mixing zone in continuous transfers (i.e., transfers in which the pump does not stop) is predominantly governed by the phenomenon of mass dispersion. This phenomenon results from the combination of the diffusion process in the radial direction with the existence of a non-uniform velocity profile of the mixture in developed laminar or turbulent flow (Aunicky, 1970; Baptista et al., 2000a and 2000b; Baptista et al., 2001; Botros, 1984; Carvalho et al., 2002; Freitas Rachid et al., 2001a and 2001b; Freitas Rachid et al., 2002a and 2002b; Maron and Galianov, 1970; Netchval et al., 1972; Ovadi and Török, 1977; Sjenitzer, 1958; Smith and Schulze, 1948). 


\subsection{Balance equations}

Generally, a mixture can be considered as an aggregate composed of various materials, defined as the constituents which may be present in different phases, such as fluid-fluid, solid-fluid, solid-solid, among others. To facilitate the understanding of key issues, consider a real mixture at a given time occupying a region $R$ of the space, as shown in Figure 4.

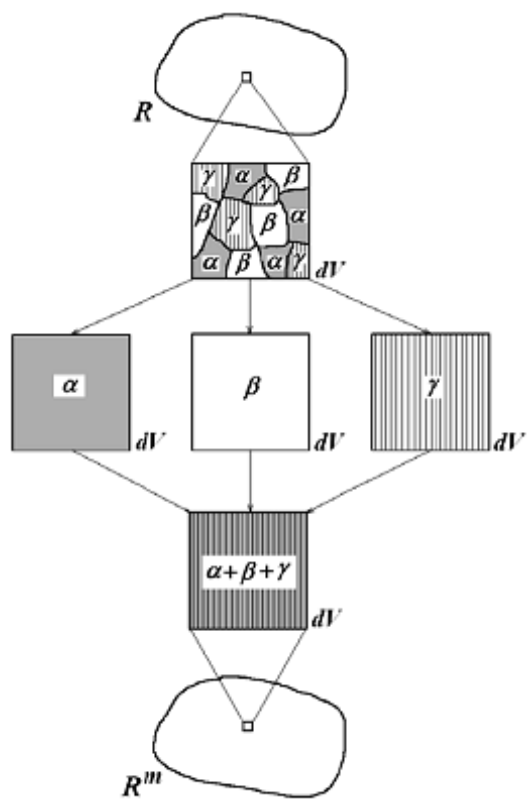

Figure 4. Constituents composition in a real and idealized mixture.

In a sample of the mixture, extracted from the vicinity of position $x \hat{\mathrm{I}} R \hat{\mathrm{I}} \mathrm{R}^{k}$, " $k \hat{\mathrm{I}}\{1,2,3\}$ notes that the mixture can be composed of different constituents $\alpha, b$ and $\gamma$, that occupy separate regions of an infinitesimal volume $d V$. Differently from what occurs in real situations, this is accepted as a basic premise of the Theory of Mixtures, and the three constituents $\alpha, b$ and $\gamma$ occupy fully and simultaneously the same infinitesimal volume $d V$ in an idealized region $R^{m}$ İ $\mathrm{R}^{k}$, similar to $R$, as seen in Figure 4. The interfaces among them observed in the volume element in $R$ are no longer noticed in the idealized volume element $R^{m}$, since a homogenization process was conducted in the passage from $R$ to $R^{m}$. Thus, the mixture in $R^{m}$ can be interpreted as a current configuration in the usual sense of the classical theory of Continuum Mechanics, in which each spatial position $x \hat{\mathrm{I}} R^{m} \grave{\mathrm{I}} \mathrm{R}^{k}$,

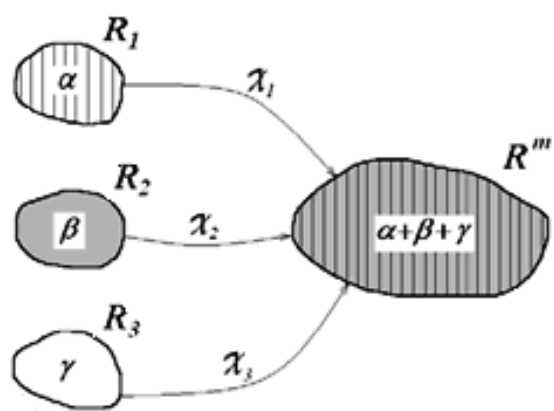

Figure 5. Representation of multiple reference configurations.

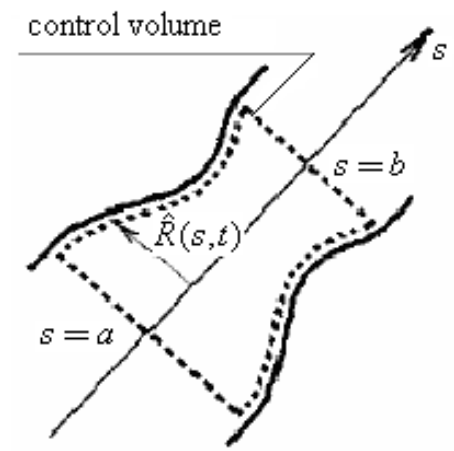

Figure 6. Representation of a control volume within the duct.

" $k \hat{\mathrm{I}}\{1,2,3\}$ is occupied at any time for each particle of each constituent, with independent thermo-mechanical properties. Alternatively, each component can be represented in different references configurations $R_{i}$ (in this case, with $i \hat{\mathrm{I}}\{1,2,3\}$ for a mixture composed of three constituents $\alpha, b$ and $\gamma$ ), as shown in Figure 5 .

Analogously to the idealized representation of a mixture illustrated in Figure 4, the region $R^{m}$ in this study represents a control volume bounded by the inner wall of a straight tube of inner radius $\hat{R}(s, t)$, with $R(s)=\hat{R}(s, t=0)$ designating the radius of the tube in a non-deformed configuration, and cross sections $s=a$ and $s=b$, with $b>a$. The internal cross section area of the duct is denoted by $A=(s, t)$, with $A=\pi \hat{R}^{2}$. In this characterization, $s \hat{\mathrm{I}}(0, L)$ ( $L$ is the length of the tube) represents the spatial coordinate measured along the centerline of the tube and $t$ is time (see Figure 6). 
The control volume illustrated in Figure 6 is occupied by a mixture consisting of $2 n$ constituents ( $n$ constituents for each product, A and B) moving through the duct of variable cross section area along the spatial coordinate $s$ (due to its original form) and time $t$ (as a result of hydrodynamic loads on the inside). Herein are presented the mechanics basic laws of Theory of Mixtures, namely: mass balance, balance of the amount of linear motion and thermodynamics laws $\left(1^{\text {st }}\right.$ and $\left.2^{\text {nd }}\right)$.

\subsubsection{Mass conservation}

The parameters $\rho_{i}^{(j)}(s, t)$ and $v_{i}^{(j)}(s, t)$, with $i \in\{A, B\}$ and $j \in\{1, \ldots, n\}$, are the spatial fields of density of the constituent in the mixture (i.e., the ratio between the mass of the $i$-th constituent per unit volume of the mixture) and the speed associated with the $j$-th constituent of the $i$-th product. It then follows that the principle of mass conservation in the mixture as a whole in the integral formulation can be expressed as:

$\sum_{j=1}^{n} \sum_{i=A}^{B}\left\{\frac{d}{d t} \int_{a}^{b} \rho_{i}^{(j)} A d s+\left[\rho_{i}^{(j)} v_{i}^{(j)} A\right]_{s=b}-\left[\rho_{i}^{(j)} v_{i}^{(j)} A\right]_{s=a}\right\}=0$

with $\forall[a, b] \subset(0, L)$ and $t \in(0, \infty)$.

To take into account the possibility that there may be an exchange of mass between the constituents of the same product or between different products, the integral formulation of the principle of mass conservation for each constituent is postulated as:

$\frac{d}{d t} \int_{a}^{b} \rho_{i}^{(j)} A d s+\left[\rho_{i}^{(j)} v_{i}^{(j)} A\right]_{s=b}-\left[\rho_{i}^{(j)} v_{i}^{(j)} A\right]_{s=a}-\int_{a}^{b} \Phi_{i}^{(j)} A d s=0$

where $\forall i \in\{A, B\}, \quad j \in\{1, \ldots, n\} \quad$ and $\forall[a, b] \subset(0, L)$, with $\Phi_{i}^{(j)}$ representing the temporal rate of mass transfer of all other constituents of both products A and B to the $j$-th constituent of the $i$-th product. Assuming that there is no mass transfer from one product to another due to chemical reactions and no phase change, then the term $\Phi_{i}^{(j)}$ can be properly expressed as:

$\Phi_{i}^{(j)}=\sum_{\substack{k=1 \\ k \neq j}}^{n} \hat{\Phi}_{i}^{(j, k)}$ and represents the temporal rate of mass transfer of the $k$-th component for the $j$-th constituent, both referring to the $i-$ th product. The term $\Phi_{i}^{(j)}$ appears in the model in question to take into account the mass flow in the radial direction, since the proposed model herein is essentially onedimensional.

Assuming that the spatial fields appearing in Equation (4) have sufficient regularity, it is possible to show that the differential form of the principle of mass conservation for each constituent is expressed as:

$\frac{\partial \rho}{\partial t}\left(\rho_{i}^{(j)} A\right)+\frac{\partial}{\partial s}\left(\rho_{i}^{(j)} v_{i}^{(j)} A\right)-A \Phi_{i}^{(j)}=0$

with $\forall i \in\{A, B\}, \quad j \in\{1, \ldots, n\} \quad$ and $\forall(s, t) \in(0, L) \times(0, \infty)$.

Taking the sum in $i$ and $j$ of Equation (4) and combining with Equation (3), and assuming sufficient regularity of the fields, one can write the differential form of the overall mixture as:

$\sum_{j=1}^{n} \sum_{i=A}^{B} \Phi_{i}^{(j)}=0$

\subsubsection{Conservation of linear movement quantity}

The local form of the principle to conservation of linear movement quantity for the $j$-th constituent of the $i$-th product in an inertial frame is reduced to the following expression:

$\rho_{i}^{(j)} \frac{d^{(i, j)} v_{i}^{(j)}}{d t}=\frac{\partial t_{i}^{(j)}}{\partial s}+b \rho_{i}^{(j)}-a_{i}^{(j)}-m_{i}^{(j)}-\sum_{\substack{k=1 \\ k \neq j}}^{n} \hat{\Phi}_{i}^{(j, k)}\left(v_{i}^{(j)}-\hat{\Gamma}_{i}^{(j, k)}\right)$

with $\forall i \in\{A, B\}, \quad j \in\{1, \ldots, n\} \quad$ and $\forall(s, t) \in(0, L) \times(0, \infty)$

where $\rho_{i}^{(j)}$ is the density of the $j$-th constituent of the $i$-th product, $b$ is the projection of the body force per unit mass in the axial direction of the tube, $t_{i}^{(j)}$ is the surface force per unit area cross section exerted on the $j$-th constituent of the $i$-th product in the vicinity of $s=a$ and $s=b, a_{i}^{(j)}$ is the friction force per unit volume exerted by the 
reactive nature on the side wall of the duct, $m_{i}^{(j)}$ represents the internal interaction force per unit volume exerted by all others constituents of products $\mathrm{A}$ and $\mathrm{B}$ on the $j$-th constituent of the $i$-th product, $\Gamma_{i}^{(j)} \Phi_{i}^{(j)}$ is the term that defines the amount of linear motion per unit volume supplied to the $j$-th constituent of the $i$-th product due to mass flow $\Phi_{i}^{(j)}$, and the $\frac{d^{(i, j)} v_{i}^{(j)}}{d t}$ term represents the material derivative in Eulerian coordinates of the velocity of the $j$-th constituent of the $i$-th product.

\subsubsection{First law of thermodynamics}

The local form for each component product can be expressed as:

$\rho_{i}^{(j)} \frac{d^{(i, j)} u_{i}^{(j)}}{d t}=t_{i}^{(j)} \frac{\partial v_{i}^{(j)}}{\partial s}+m_{i}^{(j)} v_{i}^{(j)}+a_{i}^{(j)} v_{i}^{(j)}+\rho_{i}^{(j)} r_{i}^{(j)}-{ }_{L} q_{i}^{(j)}-\frac{1}{\mathrm{~A}} \frac{\partial}{\partial s}\left({ }_{s} q_{i}^{(j)} \mathrm{A}\right)+$

$+\frac{{ }_{R} t_{i}^{(j)}}{\mathrm{A}} \frac{d^{(i, j)} \mathrm{A}}{d t}+\sum_{\substack{k=1 \\ k \neq j}}^{n} \hat{\Phi}_{i}^{(j, k)}\left(\hat{G}_{i}^{(j, k)}+\frac{1}{2}\left(v_{i}^{(j)}\right)^{2}-u_{i}^{(j)}-\hat{\Gamma}_{i}^{(j, k)} v_{i}^{(j)}\right)+\xi_{i}^{(j)}$

with $\forall i \in\{A, B\}, \quad j \in\{1, \ldots, n\} \quad$ and $\forall(s, t) \in(0, L) \times(0, \infty)$, where $r_{i}^{(j)}$ is the temporal rate of generation/absorption of heat per unit mass associated with the $j$-th constituent of the $i$-th product, ${ }_{s} q_{i}^{(j)}$ is the heat flux per unit tube cross section area, ${ }_{L} q_{i}^{(j)}$ is the radial heat flow through the pipe wall, $\hat{G}_{i}^{(j, k)}$ represents the sum of kinetic and specific internal energy of the $k$-th constituent of the $i$-th product immediately before becoming part of the $j$-th constituent of the $i$-th product, and $u_{i}^{(j)}$ represents the specific internal energy of the $j$-th constituent of the $i$-th product.

\subsubsection{Second law of thermodynamics}

Defining $s_{i}^{(j)}$ as the specific entropy of the $j$-th constituent of the $i$-th product, and assuming the basic premise that all constituents of both products share the same temperature, the second law can be postulated for the overall mixture in the integral form as:

$\sum_{j=1}^{n} \sum_{i=A}^{B}\left\{\frac{d}{d t} \int_{a}^{b} \rho_{i}^{(j)} s_{i}^{(j)} A d s+\left[\rho_{i}^{(j)} s_{i}^{(j)} A v_{i}^{(j)}\right]_{s=b}-\left[\rho_{i}^{(j)} s_{i}^{(j)} A v_{i}^{(j)}\right]_{s=a}\right\} \geq$ $\geq \sum_{j=1}^{n} \sum_{i=A}^{B}\left\{-\left[\int_{a}^{b} \frac{{ }_{L} q_{i}^{(j)}}{\theta} d s+\int_{a}^{b} \frac{\partial}{\partial s}\left(\frac{{ }_{s} q_{i}^{(j)} A}{\theta}\right) d s\right]+\int_{a}^{b} \frac{\rho_{i}^{(j)} r_{i}^{(j)} A}{\theta} d s+\right.$

$\left.+\int_{a}^{b} \frac{m_{i, R}^{(j)} v_{i}^{(j)}}{\theta} A d s+\int_{a}^{b} \frac{a_{i}^{(j)} v_{i}^{(j)}}{\theta} A d s\right\}$

with $\forall[a, b] \subset(0, L)$ and $t \in[0, \infty]$, where $m_{i, R}^{(j)}$ is the portion of the strength of interaction between adjacent constituents, given from:

$m_{i}^{(j)}=m_{i, R}^{(j)}+m_{i, s}^{(j)}$

where $m_{i, s}^{(j)}$ is the portion of the strength of interaction between axial constituents.

It should be noted that the postulation of the second law for the overall mixture, expressed by Equation (10), implies the classical form adopted for the second law for the mixture as a whole (Atkin and Craine, 1976; Rajagopal and Tao, 1995).

\subsection{Mixing volume}

Assuming that tolerable levels of purity of product $A$ in the mixture $\left(C_{A B}\right)$ and product $B$ in the mixture $\left(C_{B A}\right)$ are equal, $C_{A B}=C_{B A}=C$, then the mixing length $L_{m}$ can be calculated and expressed by Equation (12).

$$
L_{m}=4 \sqrt{K L D} \cdot e^{-1}(2 C-1)
$$

where $K$ is the virtual diffusion coefficient of an axial mass in dimensionless form, $L$ is the pipeline length, $D$ is the pipe diameter, erf ${ }^{-1}$ is the reversed error function and $C$ is the mixture concentration $\left(C_{A B}=C_{B A}=C\right)$.

The mixing volume $\left(V_{m}\right)$ is then calculated by multiplying the mixing length by the area of the pipe cross section, as in Equation (13).

$V_{m}=L_{m} \cdot A$

In this paper, we aim to show the influence of the speed with which the batch transfer is conducted and also the influence of the pipeline extension on the mixing volume. The analytical solution presented above could then be used in a situation where the fluid shifter (product B) and displaced fluid (product $A$ ) are diesel and gasoline, whose kinematic viscosities are $v_{B}=8.7 \mathrm{cSt}$ and $v_{A}$ $=0.9 \mathrm{cSt}$, respectively. It is assumed that the 
diameter of the duct is $0.58 \mathrm{~m}$ and the viscosity of the mixture $(\mathrm{U})$ is constant and equal to $3.45 \mathrm{cSt}$, assuming $C_{A}=C_{B}=0.5$, based on the Gambil correlation (1959), which is given by the following expression:

$v^{1 / 3}=C_{A} v_{A}^{1 / 3}+C_{B} v_{B}^{1 / 3}$

Furthermore, the mixing volumes are calculated for different average velocity values of the fluid $(0.01 ; 0.10 ; 1.00 ; 2.00$ and $3.00 \mathrm{~m} / \mathrm{s})$ and for different pipeline extensions $(100,200,400$ and $800 \mathrm{~km})$. The dispersion coefficient for the calculated Reynolds number $(R e)$ and the estimated Schmidt number $(\mathrm{Sc}=100)$ were obtained through the correlation of Krantz and Wasan (1974). Table 1 shows the values of $R e$ and $K$ for the different speeds mentioned above.

Table 1. Values of $R e$ and $K$ for the different speeds.

\begin{tabular}{|c|c|c|}
\hline$\left\langle\overline{\boldsymbol{v}}_{s}\right\rangle$ & $R e$ & $K$ \\
\hline 3.00 & $4.42 \mathrm{E}+05$ & 0.16 \\
\hline 2.00 & $2.94 \mathrm{E}+05$ & 0.17 \\
\hline 1.00 & $1.47 \mathrm{E}+05$ & 0.18 \\
\hline 0.10 & $1.47 \mathrm{E}+04$ & 0.70 \\
\hline 0.01 & $1.47 \mathrm{E}+03$ & 10.0 \\
\hline
\end{tabular}

\section{RESULTS AND DISCUSSION}

The mixing volumes had been calculated using our own software developed in Fortran ${ }^{\circ}$ for different speeds, considering $C_{A B}=C_{B A}$ as the permissible concentrations ranging from 1 to $10 \%$ after half of the conventional mixture had covered a distance of 100, 200, 400 and $800 \mathrm{~km}$ respectively. The results are depicted in Figure 7 , and are also summarized in Table 2, for concentrations equal to 1,5 and $10 \%$, for average speeds of $3.00 ; 2.00 ; 1.00 ; 0.10$ and $0.01 \mathrm{~m} / \mathrm{s}$, and pipe lengths of 100, 200, 400 and $800 \mathrm{~km}$. The highlighted cells in Table 2 indicate the different speeds for each permissible concentration.

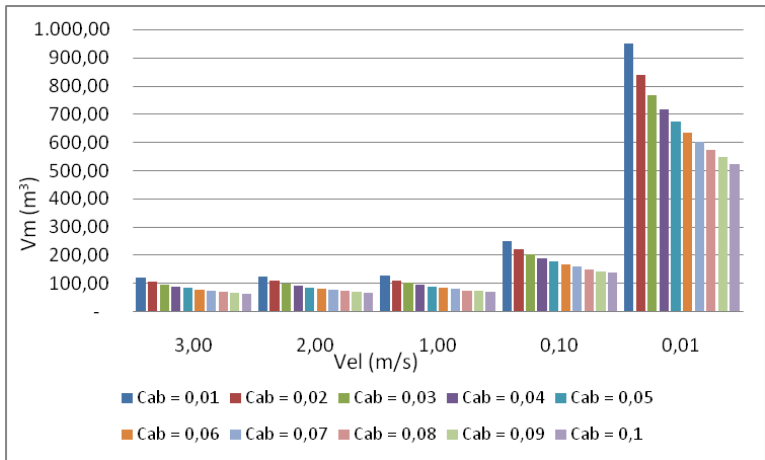

Figure 7. Changes in mixing volume as a function of flow velocity for each value of permissible concentration.

In Figure 7, one can see that the mixing volume changes as a function of flow velocity for each value of permissible concentration ranging between 1 and $10 \%$.

The graphs shown in Figure 8 illustrate the mixing volume computed as a function of the Reynolds number after half of the conventional mixture had covered $100 \mathrm{~km}$ and $800 \mathrm{~km}$ of the pipeline, respectively. The graphs for $200 \mathrm{~km}$ and $400 \mathrm{~km}$ are not shown because they have the same curve profile of the previous ones.
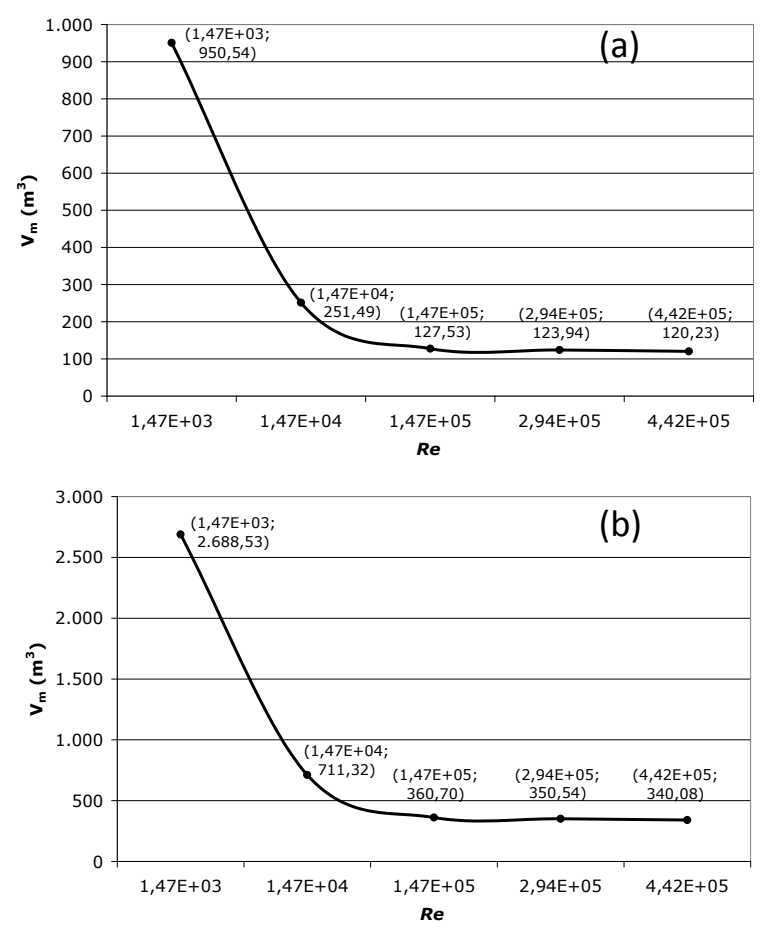

Figure 8. Mixture volume as a function of Reynolds number for (a) $100 \mathrm{~km}$ and (b) $800 \mathrm{~km}$ with $C_{\mathrm{AB}}=C_{\mathrm{BA}}=$ $1 \%$. 
Table 2. Calculated mixture volume at different $C_{\mathrm{AB}}$ concentrations.

\begin{tabular}{|c|c|c|c|c|}
\hline$C_{\mathrm{AB}}(\%)$ & $\mathrm{V}(\mathrm{m} / \mathrm{s})$ & $L(\mathrm{~km})$ & $L_{\mathrm{m}}(\mathrm{m})$ & $V_{\mathrm{m}}\left(\mathrm{m}^{3}\right)$ \\
\hline 0.01 & 3.00 & 100 & 593.21 & 120.23 \\
\hline 0.01 & 3.00 & 200 & 838.93 & 170.03 \\
\hline 0.01 & 3.00 & 400 & 1186.43 & 240.46 \\
\hline 0.01 & 3.00 & 800 & 1677.86 & 340.06 \\
\hline 0.01 & 2.00 & 100 & 611.47 & 123.93 \\
\hline 0.01 & 2.00 & 200 & 864.75 & 175.27 \\
\hline 0.01 & 2.00 & 400 & 1222.94 & 247.86 \\
\hline 0.01 & 2.00 & 800 & 1729.50 & 350.53 \\
\hline 0.01 & 1.00 & 100 & 629.2 & 127.52 \\
\hline 0.01 & 1.00 & 200 & 889.82 & 180.35 \\
\hline 0.01 & 1.00 & 400 & 1258.40 & 255.05 \\
\hline 0.01 & 1.00 & 800 & 1779.64 & 360.69 \\
\hline 0.01 & 0.10 & 100 & 1240.80 & 251.48 \\
\hline 0.01 & 0.10 & 200 & 1754.75 & 355.65 \\
\hline 0.01 & 0.10 & 400 & 2481.59 & 502.96 \\
\hline 0.01 & 0.10 & 800 & 3509.50 & 711.3 \\
\hline 0.01 & 0.01 & 100 & 4689.77 & 950.51 \\
\hline 0.01 & 0.01 & 200 & 6632.34 & 1344.22 \\
\hline 0.01 & 0.01 & 400 & 9379.54 & 1901.02 \\
\hline 0.01 & 0,01 & 800 & 13264.67 & 2688.44 \\
\hline 0.05 & 3.00 & 100 & 419.43 & 85.01 \\
\hline 0.05 & 3.00 & 200 & 593.17 & 120.22 \\
\hline 0.05 & 3.00 & 400 & 838.87 & 170.02 \\
\hline 0.05 & 3.00 & 800 & 1186.34 & 240.44 \\
\hline 0.05 & 2.00 & 100 & 432.34 & 87.63 \\
\hline 0.05 & 2.00 & 200 & 611.43 & 123.92 \\
\hline 0.05 & 2.00 & 400 & 864.69 & 175.25 \\
\hline 0.05 & 2.00 & 800 & 1222.85 & 247.84 \\
\hline 0.05 & 1.00 & 100 & 444.88 & 90.17 \\
\hline 0.05 & 1.00 & 200 & 629.15 & 127.51 \\
\hline & & & & \\
\hline 0.05 & & \\
\hline 0.05 & & & \\
\hline 0.05 & & & \\
\hline
\end{tabular}

\begin{tabular}{|c|c|c|c|c|}
\hline$C_{\mathrm{AB}}(\%)$ & $\mathrm{v}(\mathrm{m} / \mathrm{s})$ & $L(\mathrm{~km})$ & $L_{m}(m)$ & $V_{m}\left(m^{3}\right)$ \\
\hline 0.05 & 1.00 & 400 & 889.75 & 180.33 \\
\hline 0.05 & 1.00 & 800 & 1258.30 & 255.03 \\
\hline 0.05 & 0.10 & 100 & 877.31 & 177.81 \\
\hline 0.05 & 0.10 & 200 & 1240.70 & 251.46 \\
\hline 0.05 & 0.10 & 400 & 1754.62 & 355.62 \\
\hline 0.05 & 0.10 & 800 & 2481.41 & 502.92 \\
\hline 0.05 & 0.01 & 100 & 3315.92 & 672.06 \\
\hline 0.05 & 0.01 & 200 & 4689.42 & 950.44 \\
\hline 0.05 & 0.01 & 400 & 6631.84 & 1344.12 \\
\hline 0.05 & 0.01 & 800 & 9378.84 & 1900.88 \\
\hline 0.10 & 3.00 & 100 & 326.79 & 66.23 \\
\hline 0.10 & 3.00 & 200 & 462.16 & 93.67 \\
\hline 0.10 & 3.00 & 400 & 653.59 & 132.47 \\
\hline 0.10 & 3.00 & 800 & 924.31 & 187.34 \\
\hline 0.10 & 2.00 & 100 & 336.85 & 68.27 \\
\hline 0.10 & 2.00 & 200 & 476.38 & 96.55 \\
\hline 0.10 & 2.00 & 400 & 673.7 & 136.54 \\
\hline 0.10 & 2.00 & 800 & 952.76 & 193.1 \\
\hline 0.10 & 1.00 & 100 & 346.62 & 70.25 \\
\hline 0.10 & 1.00 & 200 & 490.19 & 99.35 \\
\hline 0.10 & 1.00 & 400 & 693.23 & 140.5 \\
\hline 0.10 & 1.00 & 800 & 980.38 & 198.7 \\
\hline 0.10 & 0.10 & 100 & 683.54 & 138.54 \\
\hline 0.10 & 0.10 & 200 & 966.67 & 195.92 \\
\hline 0.10 & 0.10 & 400 & 1367.07 & 277.07 \\
\hline 0.10 & 0.10 & 800 & 1933.33 & 391.84 \\
\hline 0.10 & 0.01 & 100 & 2583.53 & 523.62 \\
\hline 0.10 & 0.01 & 200 & 3653.66 & 740.51 \\
\hline 0.10 & 0.01 & 400 & 5167.05 & 1047.24 \\
\hline 0.10 & 0.01 & 800 & 7307.32 & 1481.03 \\
\hline
\end{tabular}

According to the results presented in the data analysis, we could conclude that:

1. If the mass transfer is conducted with an average speed of $0.01 \mathrm{~m} / \mathrm{s}$, very high mixing volumes are obtained, as seen in Figure 8. Although speeds of that magnitude are not observed in transport within pipelines, they were included in these simulations only to characterize the fact that laminar flow regimes or full transitions should always be avoided, because they induce very large dispersion coefficients and, consequently, significantly higher mixing volumes;

2. It was also observed in Figure 8 that the volume of mixture increases with decreasing admissible concentration. Regardless of the permissible concentration, the higher the transfer speed, the larger the Reynolds number, and therefore the lower the mixing volume. This last statement normally surprises the common

sense of those who mistakenly associate directly the turbulence to the mixing phenomenon.

There are similarities in the profile of the curves presented in Figure 8 , and the mixing volume is sequentially higher due to greater line extension; therefore, the larger the line, the higher the contact time of fluids. In other words, regardless of the permissible concentration adopted, the greater the distance, the higher the mixing volume. Strictly speaking, Equation (12) shows that the mixing length, $L_{m}$, is proportional to the square root of the traveled distance.

\section{CONCLUSIONS}

As explained above, the mixing volume depends on the permitted concentration, the flow velocity, the pipeline extension and the Reynolds number. 
When the dependence of the mixing volume with the Reynolds number is assessed, one confirms that the mixing volume increases with increasing pipeline length. It was demonstrated that the mixing volume is reduced with increasing Reynolds number. Alternatively, as the Reynolds number increases, it was seen that, from a certain value, the mixing volume becomes almost independent of Reynolds. This fact shows that an increase in the flow velocity during the conducted batch transfer will not always result in substantial reduction of the mixture.

This paper presented the formulation of a model to describe sequential transfers of oil and oil derivatives in contemplating the possibility that the velocity profiles of the fluids are reversed due to pumping stops. The model was built based on the Theory of Continuous Structured Mixing, which assigns independent kinematics for products and describes an internal structure for the constituents that make up the products. The existence of spatial velocity fields (one field for each product) can describe the motion of the constituents of individual products, thereby providing products and more realistic velocity profiles when pump stops occur. In a thermodynamically consistent way, the model takes into account the effects of inertia forces, gravity and viscosity, and the phenomenon of diffusion in the axial and radial directions.

Contrary to what occurs in the classical formulation, the proposed model explicitly considers the nature of the velocity profile of both products, allowing for proper description of the mixing process in typical situations where pumping is interrupted.

\section{REFERENCES}

Atkin, R. J. and Craine, R. E., "Continuum Theories of Mixtures: Basic Theory and Historical Development". Quarterly Journal of Mechanics and Applied Mathematics, Vol. 29, pp. 209-244, 1976. doi:10.1093/ajmam/29.2.209

Aunicky, Z., "The longitudinal mixing of liquids flowing successively pipelines". The Canadian Journal of Chemical Engineering, 48:12 - 16, February 1970.
Baptista, R. M., Freitas Rachid, F. B., Carneiro Araujo, J. H., "Mixing Volume Evaluation under Pumping Shut-down Conditions". In: $33^{\text {rd }}$ PIPELINE SIMULATION INTEREST GROUP CONFERENCE, 2001, Salt Lake City, Utah. PSIG Pipeline Simulation Interest Group -ThirtyThird Annual Meeting. 2001. p. 1-13.

Baptista, R. M., Freitas Rachid, F. B. and Carneiro Araujo, J. H., "Interface contamination modeling in pipeline batch transfers," Proceedings of ETCE/OMAE2000 ASME Joint Conference, paper PR-097, Feb. 14-17, New Orleans, USA, 2000a.

Baptista, R. M., Freitas Rachid, F. B. and Carneiro Araujo, J. H., "Estimating Mixing Volumes Between Batches in Multiproduct Pipelines". In: IPC2000 - ASME INTERNATIONAL PIPELINE CONFERENCE, 2000, Calgary. Proceedings of the ASME International Pipeline Conference. New York: ASME - American Society of mechanical Engineers, 2000b. v. 2, p. 1165-1170.

Botros, K. K., "Estimating contamination between batches in products lines". Oil \&Gas Journal, (13):112-114, Feb 1984.

Carvalho, L. C. da Silva; RACHID, F. B. F.; ARAUJO, J. H. C., "Mixture Viscosity Influence on the Contaminated Mixing Volume in Batch Transfers". In: II CONGRESSO NACIONAL DE ENGENHARIA MECÂNICA - CONEM 2002, João Pessoa (Brazil), 2002, p. 1-10.

Coimbra, A. L., "Novas Lições de Mecânica do Contínuo". Editora Edgard Blücher Ltda., 1981. (in Portuguese)

Drew, A. D. and Passman, S. L., "Theory of Multicomponent Fluids". New York: Springer, 1998.

Freitas Rachid, F. B., Araujo, J. H. C., Baptista, R. M., "A Fully-Coupled Transient Model for Predicting Interface Contamination in Product Pipelines". In: International Mechanical Engineering Congress and Exposition, New York: The American Society of Mechanical Engineers. v. 1, p. 1-8, 2001a.

Freitas Rachid, F. B., Araujo, J. H. C., Baptista, R. M., "Interface Contamination in Batch Transfers under Non-continuous Pumping". In: $16^{\text {th }}$ BRAZILLIAN CONGRESS OF MECHANICAL 
ENGINEERING - COBEM 2001, Uberlândia, MG. pp. 248-256, 2001b.

Freitas Rachid, F. B., Araújo, J. H. C., Baptista, R. M., " Predicting Mixing Volumes in Serial Transport in Pipelines". Journal of Fluids Engineering Transactions of the ASME, United States of America, vol. 124, p. 528-534, June 2002a.

Freitas Rachid, F. B., Araújo, J. H. C., Baptista, R. M., "The Influence of Pipeline Diameter Variation on the Mixing Volume in the Batch Transfers". In: IPC2002 - ASME - International Pipeline Conference. New York, 2002b.

Gambil, W. R., "How to estimate mixtures viscosities". Chemical Engineering, Vol. 66, pp. 151-152, 1959.

Krantz, W. B. and Wasan, D. T., "Axial dispersion in the turbulent flow of power - law fluids in straigtht tubes". Ind. Eng. Chem.,Fundam., 13(1):56-61, 1974. doi:10.1021/i160049a011

Maron, V. I. and Galianov, A. I., "Coeficientes de mistura no escoamento de líquido em tubos". Izvestia Vischikh Utchebnuikh Zavedenii Neft'l Gaz. G'idrávlika, G'idrodinamika i Termodinamika v Neftianoi Promuichlennosti, 2:74-78, 1970. (in Russian) Banco de Traduções, CENPES, Divisão de Informação Técnica e Propriedade Industrial Setor de Informação e Divulgação Técnica.

Netchval, M. V., Tugunov, P.I. and Slesáreva, V. G., "Formulação da mistura em processo de bombeamento ordenado dos derivados de petróleo de viscosidade variada". Neftyanoy Khozyaistvo,50(8):57-59, 1972. (in Russian) Banco de Traduções n.o 1463, CENPES, Divisão de Informação técnica e Propriedade Industrial - Setor de Informação e Divulgação Técnica.

Ovádi, Z. and Török, E., "Exame do Transporte em oleodutos sob o ponto de vista da qualidade do produto". Köolaj és Földgáz, 10(4):121-123, 1977. (in Hungarian). Banco de Traduções n.o 236.699,CENPES, Divisão de Informação Técnica e Propriedade Industrial - Setor de Informação e Divulgação Técnica.

Rajagopal, K. R. and Tao, L., "Mechanics of mixtures". World Scientific Publishing Co., 1995.

Sjenitzer, F., "How much do products mix in a pipeline?". The pipeline Engineer, pages D31-D34, December 1958.

Smith, S.S and Schulze, R. K., "Interfacial mixing characteristics of products in products pipelines Part 1". The Petroleum Enginner, 20:94-104, October 1948.

Tepedino, A. F.; Baptista, R. M.; Freitas Rachid, F. B. and ARAUJO, J. H. C., "Interfaces em Oleodutos: Otimizando o Ponto de Corte". Proceedings of the Rio Pipeline Conference \& Exposition of 2007. Rio de Janeiro: Instituto Brasileiro de Petróleo, Gás e Biocombustíveis, 2007. p. 1-10. (in Portuguese) 